\title{
Metabolic Activation of Proestrogenic Diphenyl and Related Compounds by Rat Liver Microsomes
}

\author{
Shigeyuki Kitamura, ${ }^{*, a}$ Seigo Sanoh, ${ }^{a}$ Ryuki Kohta, ${ }^{a}$ Tomoharu Suzuki, ${ }^{a}$ Kazumi Sugihara, ${ }^{a}$ \\ Nariaki Fujimoto, ${ }^{b}$ and Shigeru Ohta ${ }^{a}$ \\ ${ }^{a}$ Graduate School of Biomedical Sciences and ${ }^{b}$ Research Institute for Radiation Biology and Medicine, Hiroshima University, Kasumi \\ 1-2-3, Minami-ku, Hiroshima 734-8551, Japan
}

(Received April 14, 2003; Accepted April 24, 2003)

In this study, liver microsome-mediated activation of diphenyl (DP), diphenylmethane (DPM) and 2,2diphenylpropane (DPP) to estrogens was demonstrated. These three compounds were negative in estrogen reporter assay using estrogen-responsive human breast cancer cell line MCF-7. However, they exhibited estrogenic activity after incubation with liver microsomes of 3-methylcholanthrene-treated rats in the cases of DP and DPM, or of phenobarbital-treated rats in the cases of DP and DPP, in the presence of NADPH. When these compounds were incubated with liver microsomes in the presence of NADPH, monohydroxyl and dihydroxyl derivatives were formed. These hydroxylated metabolites, 4-hydroxydiphenyl, 3-hydroxydiphenyl, 2-hydroxydiphenyl, 4-hydroxydiphenylmethane, 2-(4-hydroxyphenyl)-2-phenylpropane (4-OH-DPP), 4,4'-dihydroxydiphenyl, 4,4'-dihydroxydiphenylmethane and 2,2-bis(4-hydroxyphenyl)propane (bisphenol A), all exhibited estrogenic activity in MCF-7 cells. Binding assay of these hydroxylated compounds with rat uterus estrogen receptor was also positive. These results suggest that the estrogenic activities of DP, DPM and DPP were due to the formation of hydroxylated metabolites by the liver cytochrome P450 system.

Key words — diphenyl, estrogenic activity, metabolic activation, human breast cancer cell line MCF-7, endocrine disruption, cytochrome $\mathrm{P} 450$

\section{INTRODUCTION}

Some chemicals in the environment are able to mimic the biological activity of hormones such as sex hormones and thyroid hormone, thereby interfering with hormone receptor function. These endocrine disrupters include several persistent chlorinated pesticides, such as kepone, $o, p^{\prime}$-dichlorodiphenyltrichloroethane ( $o, p^{\prime}$-DDT), dieldrin and methoxychlor, some polychlorinated biphenyl congeners such as polychlorinated diphenyl (PCBs) and dibenzodioxins, and industrial compounds used in the plastics and detergent industries, such as alkylphenols and bisphenol A. ${ }^{1-3)}$ Among these compounds, those which are lipophilic and persistent may be accumulated through the food web, posing a health threat to humans and animals. Endogenous estrogens have been shown to have multiple sites of activity and to

*To whom correspondence should be addressed: Graduate School of Biomedical Sciences, Hiroshima University, Kasumi 1-2-3, Minami-ku, Hiroshima 734-8551, Japan. Tel.: +81-82257-5328; Fax: +81-82-257-5329; E-mail: skitamu@hiroshimau.ac.jp exert biological effects. Many so-called xenoestrogens produce a wide variety of toxic effects in animals. They may be playing a role in the increasing incidence of hormonally related cancers such as breast cancer and testicular cancer, and other problems of the reproductive system in humans. It is therefore important to screen environmental contaminants for estrogenic activity. Their metabolites also need to be identified and screened. We recently showed that trans-stilbene, which is the parent compound of diethylstilbestrol, and trans-stilbene oxide were not estrogenic, but exhibited a potent estrogenic activity after metabolic activation by a liver microsomal oxidation system. ${ }^{4,5)}$ In that report, we suggested that the estrogenic activity was due to the hydroxylated metabolites, trans-4-hydroxystilbene and trans-4,4'-dihydroxystilbene, formed by cytochrome P450 1A1/2. Furthermore, we demonstrated that styrene oligomers were metabolically activated to estrogens by rat liver microsomes, especially cytochrome P450 2B1. ${ }^{6}$ These results demonstrate the importance of considering proestrogenic potential, when screening for xenoestrogens in the environment. 
Diphenyl (DP) is used as an antifungal agent for citrus fruits, and is also used as wrapping paper for impregnated fruit. Under poor hygienic conditions, its production caused the toxicity for workers. ${ }^{7,8)}$ It is known to induce calculi and tumors in the urinary bladder of rats. ${ }^{9}$ Diphenylmethane (DPM) is also used as a dye carrier and synthetic intermediate, similarly to DP. DP is metabolized via multiple pathways, resulting in the production of various derivatives, such as conjugates (sulfate and glucuronide) of hydroxylated diphenyls. 4-Hydroxydiphenyl, 4,4'dihydroxydiphenyl and 3,4-dihydroxydiphenyl were identified as urinary metabolites of DP in rats and rabbits. ${ }^{10)}$ Furthermore, 2-hydroxydiphenyl, 2,4'dihydroxydiphenyl and 3-hydroxydiphenyl were also identified as in vitro metabolites with liver microsomes of various animals. ${ }^{11)}$ The 2- and 3-hydroxylation activities were induced to similar extents by 3-methylcholanthrene (MC) pretreatment of the animals. Phenobarbital pretreatment primarily induced 2- and 3-hydroxylation activities, the latter more dramatically. ${ }^{12)}$ The sulfate conjugate of 4-hydroxydiphenyl is involved in the formation of urinary calculi. ${ }^{9}{ }^{9}$ The sulfate conjugate is also reported to be a candidate for medicinal treatment of breast cancer, because it shows a potent inhibitory effect on sulfation of estrogens. ${ }^{13)}$ Ozawa et al.${ }^{14)} \mathrm{re}$ ported that 2,5-dihydroxydiphenyl is a cytotoxic metabolite. However, the estrogenic activities of DP and related compounds have not been reported.

In the present study, the estrogenic activities of DP, DPM and 2,2-diphenylpropane (DPP) were examined in the presence or absence of a liver microsomal oxidase system by employing the estrogen-responsive element (ERE)-luciferase reporter assay in MCF-7 cells. We demonstrate that DP, DPM and DPP exhibit estrogenic activities after activation to their hydroxylated products by rat liver microsomal mixed function oxidase.

\section{MATERIALS AND METHODS}

Chemicals — DP (> 99\%), 4-hydroxydiphenyl (> 99\%), 3-hydroxydiphenyl (> 95\%), 2-hydroxydiphenyl (>98\%), DPM (>99\%), 4-hydroxydiphenylmethane (> 98\%), 4,4'-dihydroxydiphenyl (> 99\%), 4,4'-dihydroxydiphenylmethane (>97\%), 2-(4-hydroxyphenyl)-2-phenylpropane (4-OH-DPP, $>98 \%$ ) and 2,2-bis(4-hydroxyphenyl)propane (bisphenol A, > 99\%) were obtained from Tokyo
Chemical Industry Co. Ltd. (Tokyo, Japan), DPP (97\%) from Aldrich Chemical Co. (Milwaukee, WI, U.S.A.), $17 \beta$-estradiol (E2; > 98\%) from Sigma Chemical Co. (St. Louis, MO, U.S.A.). [17 $\beta-2,4,6,7-$ $\left.{ }^{3} \mathrm{H}\right]$ Estradiol (specific activity $=3.53 \mathrm{GBq} / \mu \mathrm{mol}$ ) was purchased from NEN/Perkin Elmer Life Sciences (Boston, MA, U.S.A.).

Animals — Sprague-Dawley rats (210-230 g, 6 weeks old) were obtained from Japan SLC, Inc. (Shizuoka, Japan). The animals were housed at $22^{\circ} \mathrm{C}$ with a 12-hr light/dark cycle, with free access to tap water and a standard pellet diet MM-3 (Funabashi Farm, Funabashi, Japan). In some experiments, male rats were given intraperitoneal administration of phenobarbital $(80 \mathrm{mg} / \mathrm{kg})$ or $3-\mathrm{MC}(25 \mathrm{mg} / \mathrm{kg})$ daily for three days before use. All experiments were conducted in accordance with the Guide for the Care and Use of Laboratory Animals of Hiroshima University.

Preparation of Liver Microsomes — The livers of male rats were excised from exsanguinated rats and immediately perfused with $1.15 \% \mathrm{KCl}$. The livers were homogenized in four volumes of the $\mathrm{KCl}$ solution using a Potter-Elvehjem homogenizer. The microsomal fraction was obtained from the homogenate by successive centrifugation at $9000 \times g$ for $20 \mathrm{~min}$ and $105000 \times \mathrm{g}$ for $60 \mathrm{~min}$. The fraction was washed by resuspension in the $\mathrm{KCl}$ solution and resedimentation. The pellets of microsomes were resuspended in the solution to make $1 \mathrm{ml}$ equivalent to $1 \mathrm{~g}$ of liver. Protein contents in the liver microsomal preparations were determined by the method of Lowry et al. ${ }^{15)}$

Cell Culture — MCF-7 cells were maintained in Minimum Essential medium (MEM; Sigma Chemical Co.) containing penicillin and streptomycin with 5\% fetal bovine serum (LiGibco/Invitrogen Co., Carlsbad, CA, U.S.A.).

Assay of Estrogenic Activities of DP and Related Compounds — Assay of estrogenic activity was performed according to the previously reported method. ${ }^{6)}$ Briefly, for ERE-luciferase reporter assay using MCF-7 cells, transient transfections were performed using Transfast ${ }^{\mathrm{TM}}$ (Promega Co., Madison, WI, U.S.A.), with p(ERE) ${ }_{3}$-SV40-luc and pRL/CMV (Promega Co.) as an internal standard. Twenty-four hours after addition of the sample, the luciferase activity was measured with a Dual Luciferase assay kit $^{\text {TM }}$ (Promega Co.).

For the assay of the metabolites produced from proestrogens, substrates $(0.1 \mu \mathrm{mol})$ were incubated 
with $0.1 \mathrm{ml}$ of rat liver microsomes in the presence of $1 \mu \mathrm{mol}$ of NADPH for $30 \mathrm{~min}$ in a final volume of $1 \mathrm{ml}$ of $0.1 \mathrm{M} \mathrm{K}, \mathrm{Na}$-phosphate buffer ( $\mathrm{pH}$ 7.4). After the incubation, the mixture was extracted with $5 \mathrm{ml}$ of ethyl acetate and evaporated to dryness. The residue was dissolved in $1 \mathrm{ml}$ of ethanol and an aliquot was used for the estrogenic activity assay. The total concentration of the substrate and its metabolites was calculated from the original amount of the substrate.

\section{Competitive Binding Assay to Estrogen Recep-} tor — Rat uterus was homogenized with TEGDMo buffer ( $1 \mathrm{mM}$ disodium EDTA, $1 \mathrm{mM}$ dithiothreitol, $10 \mathrm{mM}$ sodium molybdate, $10 \%(\mathrm{v} / \mathrm{v})$ glycerol and $10 \mathrm{mM}$ Tris-HCl, $\mathrm{pH}$ 7.4). The cytosolic fraction was obtained from the homogenate by centrifugation at $105000 \times g$ for $50 \mathrm{~min}$. For the assay, $0.1 \mathrm{ml}(2 \mathrm{mg}$ protein) of the cytosolic fraction was added to the same volume of TEGDMo buffer containing $5 \mathrm{nM}{ }^{3} \mathrm{H}-\mathrm{E} 2(17.7 \mathrm{KBq} / \mathrm{ml})$ and various concentrations of test compounds. After incubation at $30^{\circ} \mathrm{C}$ for $40 \mathrm{~min}, 0.05 \mathrm{ml}$ of $1.5 \%$ charcoal and $0.15 \%$ dextran T70 mixture in TEG $[1 \mathrm{mM}$ disodium EDTA, $10 \%(\mathrm{v} / \mathrm{v})$ glycerol and $10 \mathrm{mM}$ Tris- $\mathrm{HCl}$, $\mathrm{pH}$ 7.4] was added. After incubation for $10 \mathrm{~min}$ at $4^{\circ} \mathrm{C}$ with occasional vortexing, the suspension was centrifuged at $1000 \times g$ for $10 \mathrm{~min}$. A $0.1 \mathrm{ml}$ aliquot of the supernatant was transferred to another tube, and $1 \mathrm{ml}$ of scintillator was added. The radioactivity in each tube was counted with a Wallac MicroBeta Scintillation Counter (Wallac Oy., Turuku, Finland).

Identification of Oxidative Metabolites of Proestrogens Formed by Rat Liver Microsomes The oxidative metabolites of proestrogens were isolated from a large-scale incubation mixture. This mixture consisted of $1 \mu \mathrm{mol}$ of the substrate, $5 \mu \mathrm{mol}$ of NADPH and $1 \mathrm{ml}(18-22 \mathrm{mg}$ protein) of liver microsomes of 3-MC- or phenobarbital-treated rats in a total volume of $5 \mathrm{ml}$ of $0.1 \mathrm{M} \mathrm{K}$,Na-phosphate buffer (pH 7.4). After incubation for $30 \mathrm{~min}$, the mixture was extracted with $20 \mathrm{ml}$ of ethyl acetate or diethyl ether. The supernatant was evaporated to dryness and dissolved in a small amount of methanol. The metabolites were purified by preparative HPLC, and identified by comparison with authentic samples.

Assay of Liver Microsomal Oxidase Activities toward Proestrogens — An incubation mixture consisted of $0.1 \mu \mathrm{mol}$ of a proestrogen, $0.5 \mu \mathrm{mol}$ of $\mathrm{NADPH}$ and $0.1 \mathrm{ml}$ of liver microsomes equivalent to $100 \mathrm{mg}$ liver wet weight (1.6-2.1 $\mathrm{mg}$ protein) in a final volume of $1 \mathrm{ml}$ of $0.1 \mathrm{M} \mathrm{K}, \mathrm{Na}$-phosphate buffer ( $\mathrm{pH}$ 7.4). The incubation was performed at $37^{\circ} \mathrm{C}$ for $20 \mathrm{~min}$. After incubation, $0.1 \mathrm{ml}$ of $2 \mathrm{~N} \mathrm{HCl}$ and $0.1 \mu \mathrm{mol}$ of 4-hydroxydiphenylmethane or phenothiazine as an internal standard were added and the mixture was extracted with $5 \mathrm{ml}$ of diethyl ether in the case of DP. In the case of DPM or DPP, $0.1 \mu \mathrm{mol}$ of phenothiazine or trans-4-hydroxystilbene as an internal standard was added and the mixture was extracted with $5 \mathrm{ml}$ of ethyl acetate. The extract was evaporated to dryness, the residue was dissolved in $0.1 \mathrm{ml}$ of methanol, and an aliquot $(5 \mu \mathrm{l})$ was analyzed by high-performance liquid chromatography (HPLC).

HPLC — HPLC was performed in a Hitachi L6000 chromatograph (Tokyo, Japan) fitted with a $250 \times 4.6 \mathrm{~mm}$ Shiseido Capcell Pak C18 type UG 120A $5 \mu \mathrm{m}$ column (Shiseido Co., Ltd., Tokyo, Japan) for the separation of DP and 4,4'-dihydroxydiphenyl, and DPM, 4-hydroxydiphenylmethane and 4,4'-dihydroxydiphenylmethane. The mobile phase for the separation of DP and the metabolites was acetonitrile-water $(4: 6, \mathrm{v} / \mathrm{v})$ The chromatograph was operated at a flow rate of $1.0 \mathrm{ml} / \mathrm{min}$ at a wavelength of $254 \mathrm{~nm}$. The elution times of 4,4'-dihydroxydiphenyl and 4-hydroxydiphenylmethane (an internal standard) were 10.3 and $22.6 \mathrm{~min}$, respectively. For the separation of DP, 2-hydroxydiphenyl, 3hydroxydiphenyl and 4-hydroxydiphenyl, a LiChrospher $100 \mathrm{NH}_{2}$ column $(125 \times 4 \mathrm{~mm})$ was used, and the mobile phase was $n$-hexane-2-propanol $(96: 4, \mathrm{v} / \mathrm{v})$. The chromatograph was operated at a flow rate of $0.5 \mathrm{ml} / \mathrm{min}$ at a wavelength of $254 \mathrm{~nm}$. The elution times of 2-hydroxydiphenyl, 3hydroxydiphenyl, 4-hydroxydiphenyl and phenothiazine (an internal standard) were 14.5, 19.7, 21.6 and $18.1 \mathrm{~min}$, respectively. For the separation of DPM and the metabolites, the mobile phase was acetonitrile-water $(1: 2, \mathrm{v} / \mathrm{v})$. The chromatograph was operated at a flow rate of $1.0 \mathrm{ml} / \mathrm{min}$ at a wavelength of $254 \mathrm{~nm}$. The elution times of 4,4'-dihydroxydiphenylmethane, 4-hydroxydiphenylmethane, phenothiazine (an internal standard) and DPM were 6.1, $13.1,18.6$ and $32.0 \mathrm{~min}$, respectively. For the separation of DPP and the metabolites, a $125 \times 4.0 \mathrm{~mm}$ Develosil column (Nomura Chemical Co., Ltd. Tokyo, Japan) was used, and the mobile phase was acetonitrile-water $(1: 1, \mathrm{v} / \mathrm{v})$. The chromatograph was operated at a flow rate of $0.4 \mathrm{ml} / \mathrm{min}$ at a wavelength of $254 \mathrm{~nm}$. The elution times of bisphenol A, 
trans-4-hydroxystilbene (an internal standard), 4OH-DPP and DPP were 5.8, 13.2, 15.8 and $50.0 \mathrm{~min}$, respectively.

Mass and UV Spectra —_ A Japan Electron Optics Laboratory HX-100 mass spectrometer (JEOL, Tokyo, Japan) in electron impact mode was used for structure analysis of the metabolites. Mass spectroscopy was carried out at a collision energy of $70 \mathrm{eV}$ and an acceleration voltage of $10 \mathrm{kV}$. UV spectra were determined with a Beckman DV-60 spectrophotometer in ethanol.

\section{RESULTS}

\section{Estrogenic Activity of DP, DPM and DPP with or without a Microsomal Activation System}

Estrogenic activity of DP, DPM and DPP in the presence or absence of a rat liver microsomal oxidation system was examined using ERE-luciferase reporter assay with MCF-7 cells. These compounds did not show estrogenic activity in this assay. When DP was incubated with liver microsomes of phenobarbital- or 3-MC-treated rats in the presence of $\mathrm{NADPH}$, the extracts of the incubation mixtures exhibited significant estrogenic effects on the cells in the range of $10^{-5}-10^{-4} \mathrm{M}$. Little effect was obtained when liver microsomes of untreated rats were used (Fig. 1A). When DPM was incubated with liver microsomes of 3-MC-treated rats in the presence of $\mathrm{NADPH}$, the extracts of the incubation mixtures exhibited estrogenic effects on the cells in the range of $10^{-5}-10^{-4} \mathrm{M}$. Little effect was obtained when liver microsomes of untreated or phenobarbital-treated rats were used instead of those from 3-MC-treated rats (Fig. 1B). In contrast, DPP exhibited a significant estrogenic effect after incubation with liver microsomes of phenobarbital-treated rats. In this case, liver microsomes from untreated or 3-MC-treated rats were not effective (Fig. 1C). These facts suggest that DP, DPM and DPP are metabolically activated to the estrogenic compounds by rat liver microsomes.

\section{Metabolism of DP, DPM and DPP by Rat Liver Microsomes}

DP was incubated with liver microsomes of 3MC-treated rats in the presence of NADPH for the detection of the estrogenic metabolites, as described in Materials and Methods. Four peaks were detected in HPLC chromatograms of the extract of the incu- bation mixtures (Figs. 2A and 2B). These peaks were not detected in the control, which was incubated without the substrate. These metabolites were designated DP-1, DP-2, DP-3 and DP-4. The retention times of DP-1, DP-2, DP-3 and DP-4 (14.5, 19.8, 21.6 and $10.3 \mathrm{~min}$ ) corresponded to those of 2 hydroxydiphenyl, 3-hydroxydiphenyl, 4hydroxydiphenyl and 4,4'-dihydroxydiphenyl, respectively. These metabolites were also detected when microsomes of phenobarbital-treated rats were used. However, DP-3 was not formed by liver microsomes of untreated rats (data not shown).

When DPM was incubated with liver microsomes of 3-MC-treated rats in the presence of NADPH, two peaks were detected in an HPLC chromatogram of the extract of the incubation mixture. These metabolites were designated DPM- 1 and DPM-2 (Fig. 2C). The retention times of DPM-1 and DPM-2, 6.1 and $13.1 \mathrm{~min}$, corresponded to those of 4,4'-dihydroxydiphenylmethane and 4-hydroxydiphenylmethane, respectively.

DPP was also incubated with liver microsomes of phenobarbital-treated rats in the presence of NADPH. Two peaks, which were designated DPP1 and DPP-2, were detected in an HPLC chromatogram of the extract of the incubation mixtures (Fig. 2D). The retention times of DPP-1 and DPP-2 (5.8 and $15.8 \mathrm{~min}$ ) corresponded to those of bisphenol A and 4-OH-DPP, respectively. The metabolites of DP (DP-1, DP-2, DP-3 and DP-4), DPM (DPM-1 and DPM-2) and DPP (DPP-1 and DPP-2) were identified unequivocally as 2-hydroxydiphenyl, 3-hydroxydiphenyl, 4-hydroxydiphenyl, 4,4'-dihydroxydiphenyl, 4,4'-dihydroxydiphenylmethane, 4-hydroxydiphenylmethane, bisphenol A and 4-OH-DPP by mass and UV spectral comparison with authentic samples.

\section{Oxidase Activities of Rat Liver Microsomes to- wards Proestrogens}

The oxidase activities of rat liver microsomes toward DP, DPM and DPP were examined using liver microsomes of untreated, phenobarbital-treated and 3-MC-treated rats. Liver microsomes of 3-MCtreated rats exhibited significant oxidase activities toward DP and DPM in the presence of NADPH compared with those of untreated rats. The amount of 4-hydroxyl, 3-hydroxyl and 2-hydroxyl derivatives of diphenyl formed were much higher than that of the 4,4'-dihydroxyl derivative (Figs. 3A and 3B). In contrast, only marginal activity was observed with 
(A)

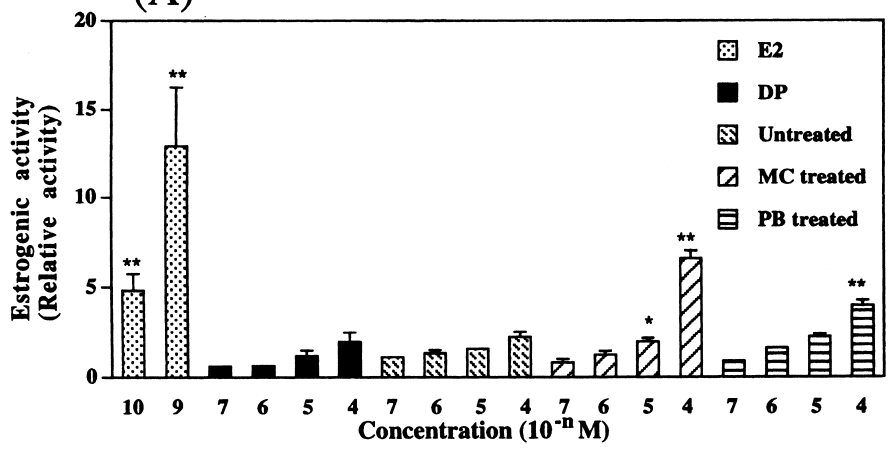

(B)

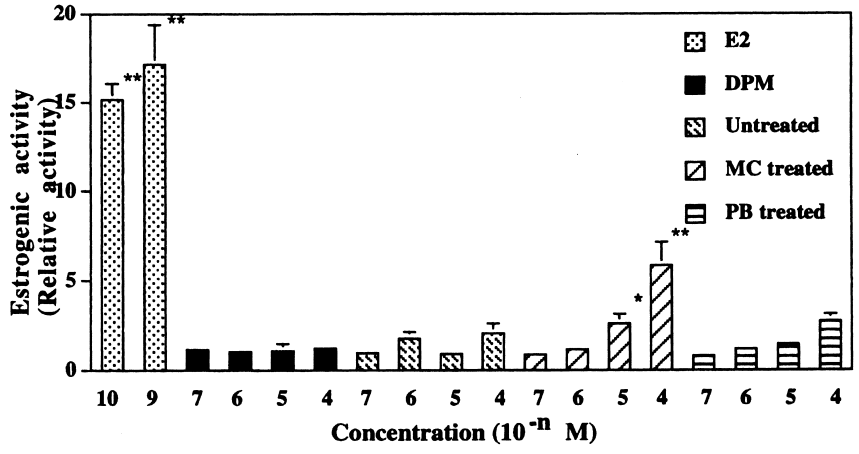

(C)

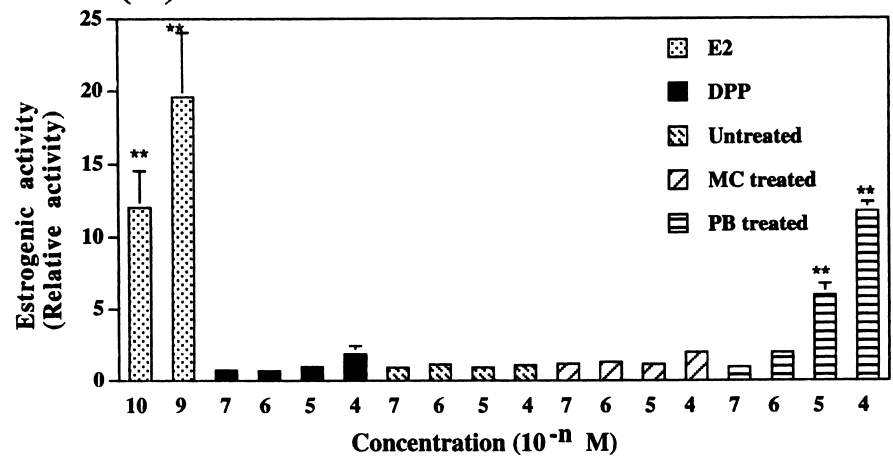

Fig. 1. Estrogenic Activity of DP and Related Compounds with or without a Rat Liver Microsomal Enzyme System Using ERELuciferase Reporter Assay in MCF-7 Cells

(A) Estrogenic activity of DP. (B) Estrogenic activity of DPM. (C) Estrogenic activity of DPP. Each bar represents the mean \pm S.D. of four experiments. Estrogenic activity was expressed as a relative activity with respect to the control using MCF-7 cells. A chemical was incubated with liver microsomes in the presence of NADPH, and the extract of the incubation mixture was subjected to the screening test. PB, phenobarbital; MC, 3-methylcholanthrene; E2, $17 \beta$-estradiol. ${ }^{*} p<0.05$ and ${ }^{* *} p<0.01$ indicate significant differences from control experiments to which no chemical was added.

NADH instead of NADPH (data not shown). Liver microsomes of phenobarbital-treated rats exhibited significant oxidase activity toward DP and DPP in the presence of NADPH compared with those of untreated rats. Oxidase activities toward DP to generate 3- and 4-hydroxydiphenyl and 4,4'-dihydroxydiphenyl were also enhanced by phenobarbital treatment. The amount of 4-OH-DPP formed by liver microsomes of phenobarbital-treated rats was much higher than that of bisphenol A (4,4'-DiOH-DPP)
(Fig. 3C). The NADPH-linked activities of rat liver microsomes toward DP, DPM and DPP were inhibited by the addition of SKF 525-A, and the activities of the microsomes of MC-treated rats toward DP and DPP were markedly inhibited by $\alpha$ naphthoflavone (data not shown). No oxidase activity of liver microsomes of untreated, 3-MC or phenobarbital-treated rats toward 4,4'-dihydroxydiphenyl, 4,4'-dihydroxydiphenylmethane or bisphenol A was detected in this experiment. 

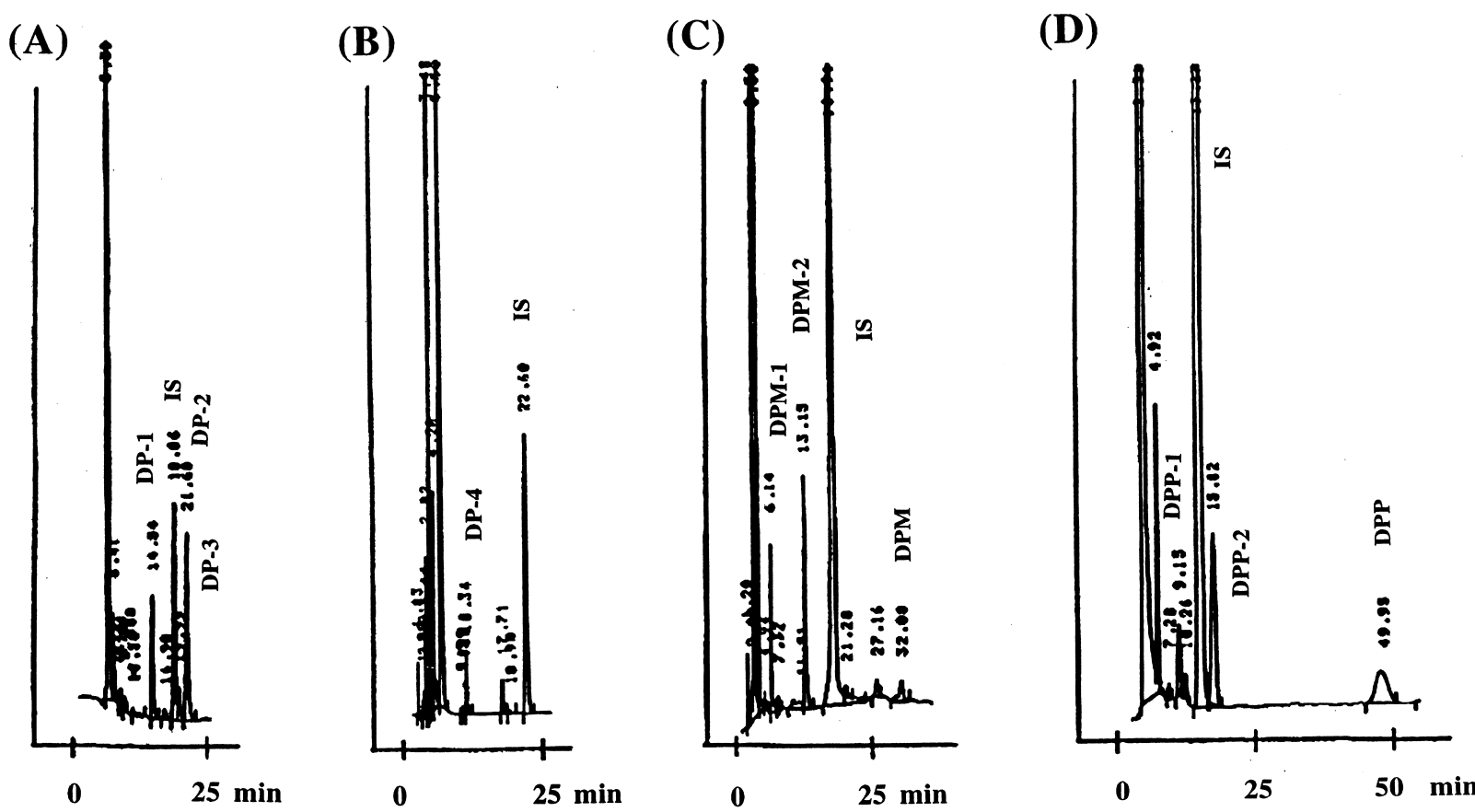

Fig. 2. HPLC of the Extract of an Incubation Mixture of DP, DPM or DPP with Liver Microsomes of 3-Methylcholanthrene-Treated Rats

(A) Chromatogram of the metabolite of DP using a normal-phase column for determination of DP-1, DP-2 and DP-3. (B) Chromatogram of the metabolite of DP using a reverse-phase column for determination of DP-4. (C) Chromatogram of the metabolite of DPM. (D) Chromatogram of the metabolite of DPP. The absorbance (full scale $=0.008 \mathrm{AU}$ ) was measured at $254 \mathrm{~nm}$. An incubation mixture consisting of $0.1 \mu \mathrm{mol}$ of a substrate, $0.5 \mu \mathrm{mol}$ of NADPH and $100 \mu \mathrm{l}(1.8 \mathrm{mg}$ protein) of liver microsomes was incubated for $20 \mathrm{~min}$. The extract of the mixture with diethyl ether was analyzed by HPLC as described in Materials and methods. IS: internal standard, DP-1, 2, 3 and 4: metabolite-1, 2, 3 and 4 of DP, DPM-1 and 2: metabolite 1 and 2 of DPM, DPP-1 and 2: metabolite-1 and 2 of DPP.

Estrogenic Activities of the Hydroxylated Metabolites Formed from the Proestrogens with Liver Microsomes

The estrogenic activities of the hydroxylated metabolites of the proestrogens were examined using ERE-luciferase reporter assay in MCF-7 cells. 4Hydroxydiphenyl, 4-hydroxydiphenylmethane, 4,4'dihydroxydiphenyl, 4,4'-dihydroxydiphenylmethane, 4-OH-DPP and 4,4'-DiOH-DPP all showed estrogenic activity, and their activities were of similar order. The activity of the 4-hydroxyl derivatives was not very different from that of the $4,4^{\prime}$ dihydroxyl derivatives. However, 2-hydroxydiphenyl and 3-hydroxydiphenyl showed lower activities than 4-hydroxydiphenyl and 4,4'dihydroxydiphenyl. These compounds were cytotoxic to MCF-7 cells at concentrations above $1 \times$ $10^{-5} \mathrm{M}$, except in the case of 4-OH-DPP (above $1 \times 10^{-6} \mathrm{M}$ ) (Fig. 4). When ICI 182,780, a pure estrogen receptor antagonist, was added at the concentration of $1 \times 10^{-8} \mathrm{M}$, the estrogenic activity of these compounds was markedly inhibited (data not shown). When 4,4'-dihydroxydiphenyl, 4,4'- dihydroxydiphenylmethane or bisphenol A was incubated with liver microsomes of untreated, phenobarbital-treated and 3-MC-treated rats in the presence of NADPH, its activity was not much changed (data not shown). These facts suggest that the estrogenic activities of DP, DPM or DPP were predominantly due to the 4-hydroxyl and 4,4'-dihydroxyl derivatives formed through metabolic activation by rat liver microsomes, because these metabolites were not further activated by rat liver microsomes.

\section{Competitive Binding Assay of the Hydroxylated Metabolites}

The estrogenic activities of DP, DPM, DPP and their metabolites were examined by using binding assay to estrogen receptor of rat uterus. Hydroxylated metabolites competitively inhibited the binding of ${ }^{3} \mathrm{H}-\mathrm{E} 2\left(5 \times 10^{-9} \mathrm{M}\right)$ to estrogen receptor in the range of $1 \times 10^{-6}-1 \times 10^{-4} \mathrm{M}$ (Fig. 5). The highest activity was observed with bisphenol $\mathrm{A}$, followed by 4-OH-DPP, 4,4'-dihydroxydiphenylmethane and 4,4'-dihydroxydiphenyl. 4,4'-Dihydroxyl derivatives showed high affinity for the estrogen receptor com- 
(A)

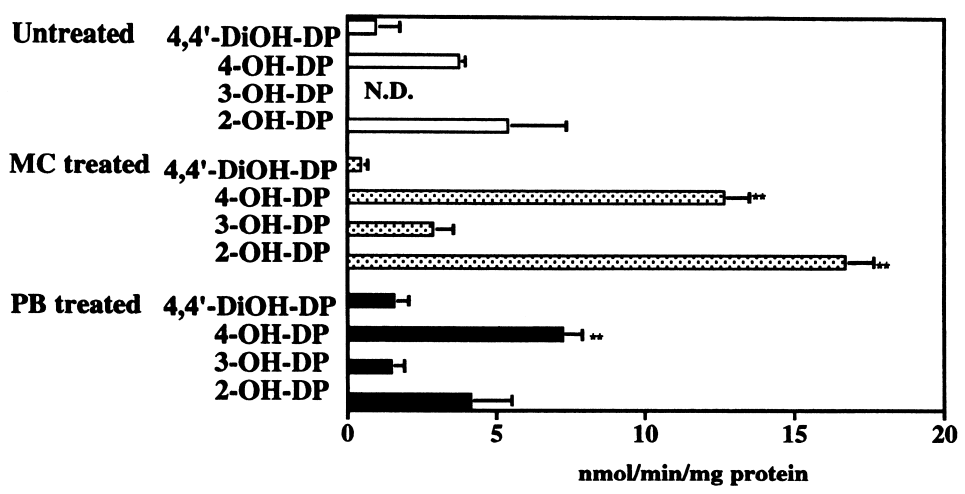

(B)

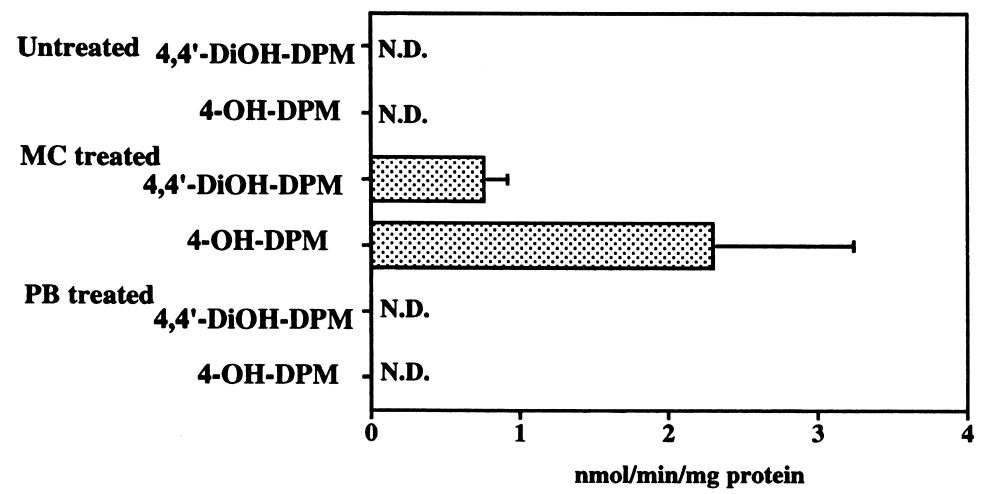

(C)

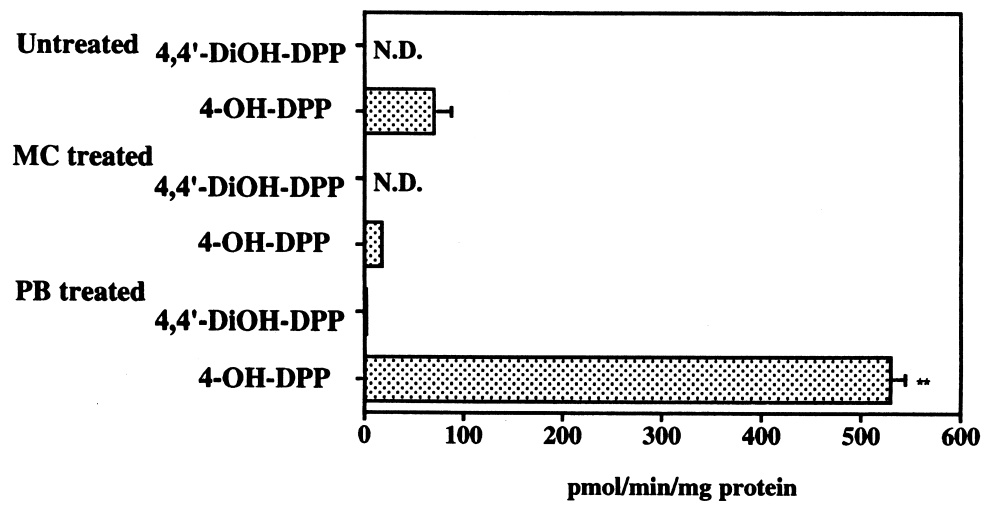

Fig. 3. Oxidase Activities of Rat Liver Microsomes towards DP and Related Compounds

(A) Oxidase activity toward DP. (B) Oxidase activity toward DPM. (C) Oxidase activity toward DPP. Each bar represents the mean \pm S.D. of four rats. A mixture containing $0.1 \mu \mathrm{mol}$ of a chemical, $0.5 \mu \mathrm{mol}$ of NADPH and $20 \mu \mathrm{l}$ of liver microsomes in $0.1 \mathrm{M}$ phosphate buffer (pH 7.4) was incubated at $37^{\circ} \mathrm{C}$ for $20 \mathrm{~min}$. The hydroxylated metabolites formed were determined using HPLC as described in Materials and Methods. N.D., not detected. PB, phenobarbital; MC, 3-methylcholanthrene; 4,4'-DiOH-DP, 4,4'-dihydroxydiphenyl; 4-OH-DP, 4-hydroxydiphenyl; 3-OH-DP, 3-hydroxydiphenyl; 2OH-DP, 2-hydroxydiphenyl; 4,4'-DiOH-DPM, 4,4'-dihydroxydiphenylmethane; 4-OH-DPM, 4-dihydroxydiphenylmethane; 4,4'-DiOH-DPP, bisphenol A; 4-OH-DPP, 2-(4-hydroxyphenyl)-2-phenylpropane. ${ }^{*} p<0.05$ and ${ }^{* *} p<0.01$ indicate significant differences from the results with untreated rats.

pared to monohydroxyl derivatives. In contrast, no inhibitory effect of DP, DPM or DPP $\left(1 \times 10^{-6}\right.$ $1 \times 10^{-4} \mathrm{M}$ ) on the binding affinity of ${ }^{3} \mathrm{H}-\mathrm{E} 2$ at the concentration of $5 \times 10^{-9} \mathrm{M}$ was observed. These experiments confirm that the estrogenic activities of DP, DPM and DPP were due to their hydroxylated metabolites generated by metabolic activation.

\section{DISCUSSION}

We have shown here that DP, DPM and DPP are converted to active estrogens by liver microsomal enzymes. Thus, these compounds seem to be typical proestrogens, which would be metabolically activated to estrogens in the body. We have already 
(A)
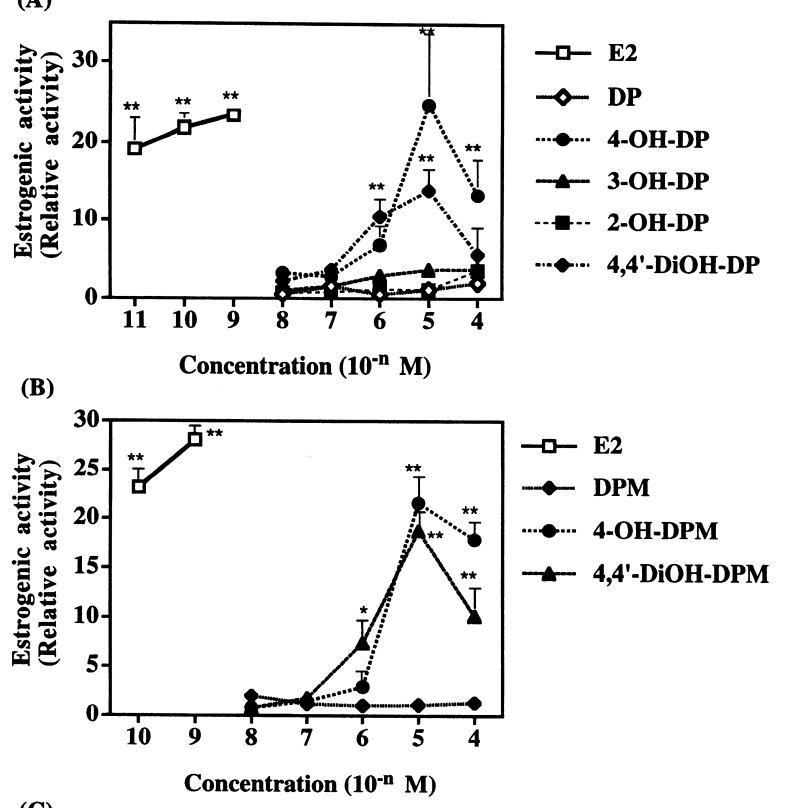

(C)

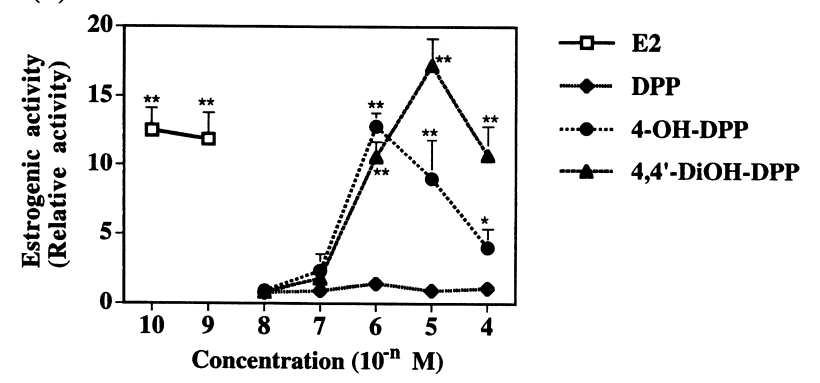

Fig. 4. Estrogenic Activity of Hydroxylated Metabolites of DP, DPM and DPP Using ERE-Luciferase Reporter Assay in MCF-7 Cells

(A) Estrogenic activity of DP and the hydroxylated metabolites. (B) Estrogenic activity of DPM and the hydroxylated metabolites. (C) Estrogenic activity of DPP and the hydroxylated metabolites. Each bar represents the mean \pm S.D. of four experiments. Estrogenic activity was expressed as a relative activity with respect to the control using MCF-7 cells. E2, $17 \beta$-estradiol; 4,4'-DiOH-DP, 4,4'-dihydroxydiphenyl; 4-OH-DP, 4-hydroxydiphenyl; 3-OH-DP, 3-hydroxydiphenyl; 2-OH-DP, 2-hydroxydiphenyl; 4,4'-DiOH-DPM, 4,4'-dihydroxydiphenylmethane; 4-OH-DPM, 4-dihydroxydiphenylmethane; 4,4'-DiOH-DPP, bisphenol A; 4-OH-DPP, 2-(4-hydroxyphenyl)-2-phenylpropane. ${ }^{*} p<0.05$ and $* * p<0.01$ indicate significant differences from control experiments to which no chemical was added.

shown that trans-stilbene and trans-stilbene oxide are activated to estrogens by rat liver microsomes, and we identified the active metabolites of transstilbene as trans-4-hydroxystilbene and trans-4,4'dihydroxystilbene. ${ }^{4)}$ Further, we demonstrated that styrene oligomers are converted to estrogens after metabolic activation by rat liver microsomes. $\left.{ }^{6}\right)$ The activation mechanism of DP and related compounds established in this study seems to be similar to that of trans-stilbene. Introduction of a phenolic hydroxyl group into a parent hydrocarbon seems generally to produce estrogenic activity. Quantitative structureactivity relationship work on the structural features of estrogen receptor ligands shows that an unhindered hydroxyl group on an aryl ring and a hydrophobic group attached para to the hydroxyl group are essential. ${ }^{16-19)}$ This requirement of a hydroxyl group was confirmed by ligand binding assay in a reporter/transcriptional system for the estrogen receptor. ${ }^{20-22)}$

In rats and rabbits in vivo, 2-, 3-, and 4-hydroxydiphenyl, and 4,4'-dihydroxydiphenyl have been found as urinary metabolites of DP. ${ }^{10,23,24)}$ The most abundant metabolite was 4,4'-dihydroxydiphenyl, followed by 4-hydroxydiphenyl. In contrast, Billings and McMahon ${ }^{11)}$ reported that DP was oxidized to 3-hydroxydiphenyl and diphenylcatechol by hamster, mouse and rabbit liver microsomes. 4Hydroxydiphenyl glucuronide and sulfate were reported to be formed by rat hepatocytes, or liver and kidney slices. ${ }^{25,26)}$ In the present study, we showed that DP, DPM and DPP are oxidized to the 4-hydroxyl derivatives, and in the case of DP to the 2-, and 3-hydroxyl derivatives as well, by cytochrome P450 of rat liver microsomes, and the 4,4'-dihydroxyl derivatives are also formed as minor metabolites. These microsomal oxidations were stimulated by the pretreatment of rats with 3-MC or phenobarbital. The differential effects of these inducers on the DP hydroxylations are in accordance with previous findings, ${ }^{12,26-28)}$ and indicate that cytochrome P450 1A1/ 2 or $2 \mathrm{~B} 1$ catalyze these hydroxylations. We confirmed that human cytochrome P450 1A2 and 2B6 expressed in human lymphoblastoid cells (Gentest, Woburn, MA, U.S.A.) catalyzed the oxidations of DP and DPP, respectively (data not shown). These isozymes are known to be major isoforms of cytochrome P450 in humans. It is thus possible that metabolic activation of DP and related compounds tested in this study to active estrogens occurs in humans. However, 4,4'-dihydroxydiphenyl was reported to be a major in vivo metabolite of DP. ${ }^{23,24)}$ We cannot explain this difference between in vivo and in vitro metabolism, but their result would support the involvement of the 4,4'-dihydroxyl derivatives in the estrogenic activity of DP, DPM and DPP in vivo.

Soto et al. ${ }^{29)}$ reported that 2-hydroxydiphenyl, which is used as an antifungal, is a weak estrogen, and the related compounds 4-hydroxydiphenyl and 3-hydroxydiphenyl are also estrogenic. Estrogenic activity of $4,4^{\prime}$-dihydroxydiphenyl has also been re- 
(A)

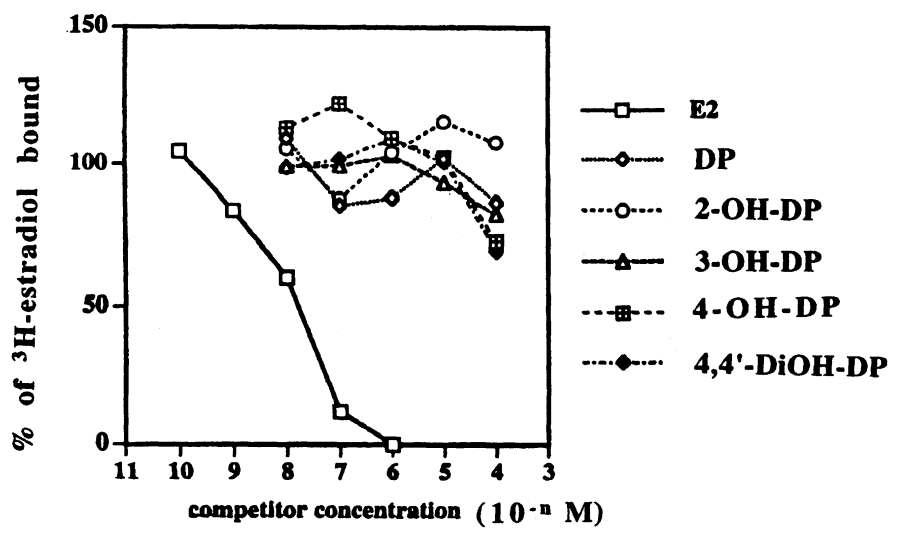

(B)

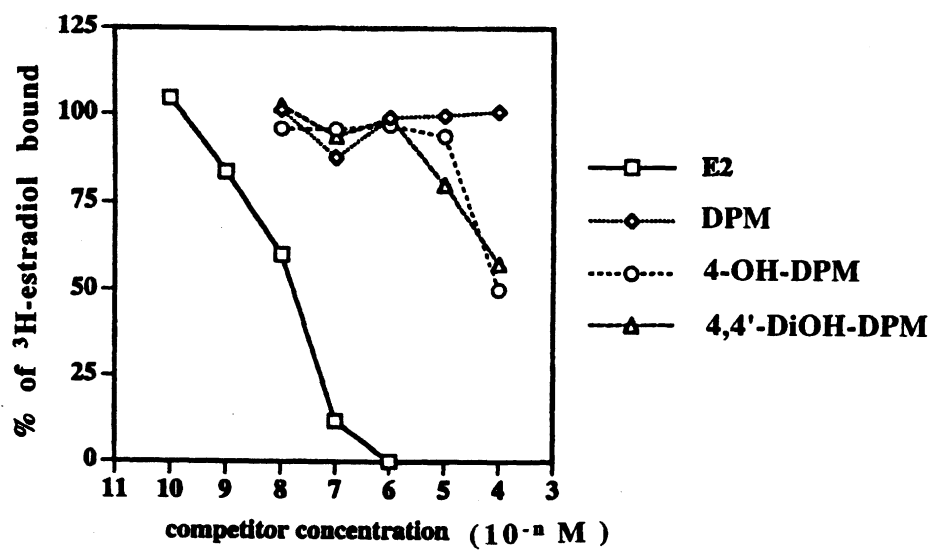

(C)

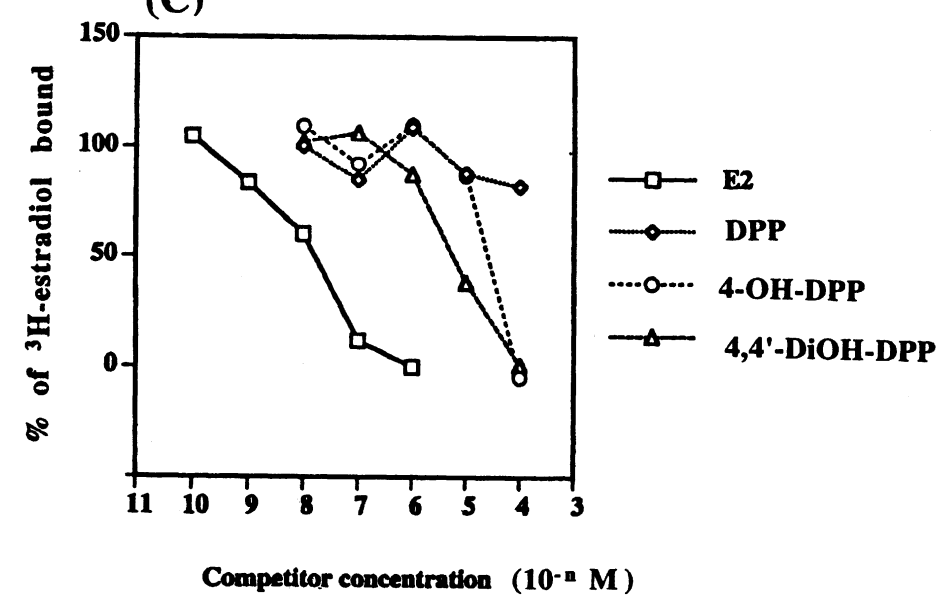

Fig. 5. Estrogen Receptor Binding Assay of Hydroxylated Metabolites of DP and Related Compounds Using Uterus Cytosol of Rats Each value represents the mean of three experiments. Binding activity was expressed as relative activity with respect to the control. (A) Binding affinity of DP and the hydroxylated metabolites. (B) Binding affinity of DPM and the hydroxylated metabolites. (C) Binding affinity of DPP and the hydroxylated metabolites. E2, $17 \beta$-estradiol; 4,4'-DiOH-DP, 4,4'-dihydroxydiphenyl; 4-OH-DP, 4-hydroxydiphenyl; 3-OH-DP, 3-hydroxydiphenyl; 2OH-DP, 2-hydroxydiphenyl; 4,4'-DiOH-DPM, 4,4'-dihydroxydiphenylmethane; 4-OH-DPM, 4-dihydroxydiphenylmethane; 4,4'-DiOH-DPP, bisphenol A; 4-OH-DPP, 2-(4-hydroxyphenyl)-2-phenylpropane.

ported. ${ }^{3)}$ These phenylphenols are used as household insecticides, especially for indoor applications, ${ }^{30)}$ and as intermediates in the manufacture of rubber and resins. Further examination is necessary to assess in detail the toxicity of phenylphenols. We showed in this paper that 4-hydroxydiphenyl is a major me- 


\section{Non estrogenic}

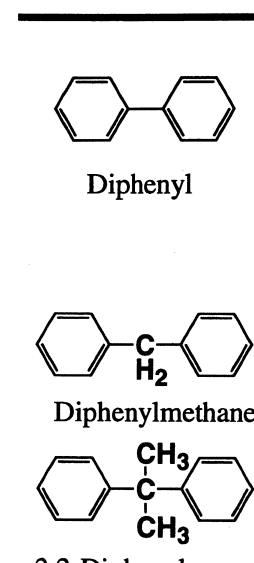

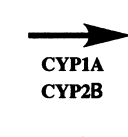
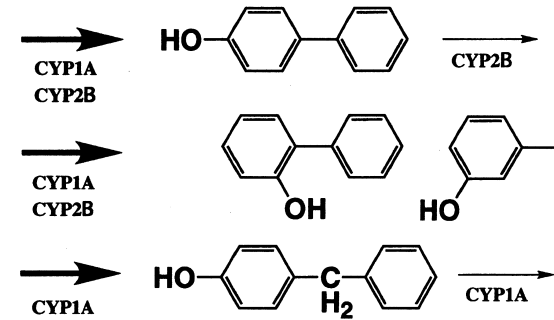

CYP1A

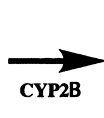

2,2-Diphenylpropane

\section{Estrogenic}

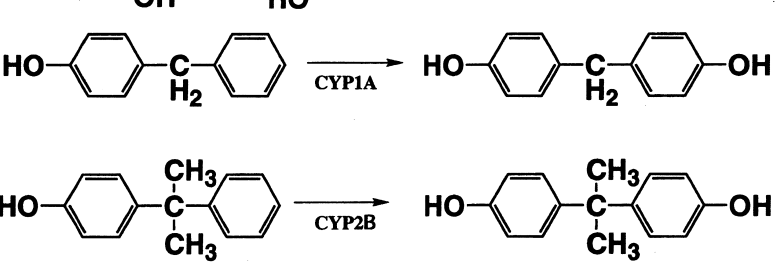

Fig. 6. Metabolic Pathways for the Activation of DP, DPM and DPP by Rat Liver Microsomes CYP, cytochrome P450.

tabolite of DP in a rat liver microsomal system. The in vivo estrogenic activity of DP and DPM has been briefly reported in the literature: ${ }^{31)}$ the weight of the ovary in ovariectomized rats dosed with 4-hydroxylated diphenyl and DPM was increased compared to that in rats dosed with vehicle alone.

A possible metabolic activation pathway of the proestrogenic chemicals examined in this study with liver microsomes is shown in Fig. 6. In the microsomal system used in this study, the estrogenic activity is likely to be mainly exhibited by the 4-hydroxyl derivatives, because the pathway leading from 4hydroxyl derivatives to $4,4^{\prime}$-dihydroxyl derivatives does not proceed effectively in this system, especially for DPP. In the case of PCB, the catechol-type metabolite was shown to induce estrogenic activity. ${ }^{32)}$ It remains possible that catechol-type metabolites of DP and related compounds may be active. However, we could not detect these metabolites in our system.

Various compounds related to those used in this study have also been shown to have estrogenic activity after the metabolic activation. $p$-Hydroxybenzophenone, which is formed from benzophenone, an ultraviolet light-absorber, in rat hepatocytes, is also estrogenic. ${ }^{33,34)} p, p^{\prime}$-dichlorodiphenyltrichloroethane $\left(p, p^{\prime}\right.$-DDT) is metabolized to $p, p^{\prime}$-dichlorodiphenyldichloroethane $\left(p, p^{\prime}\right.$-DDD) and $p, p^{\prime}$ dichlorodiphenyldichloroethylene ( $p, p^{\prime}$-DDE) by reductive dechlorination and dehydrochlorination, respectively, in animals and fish.35,36) $p, p^{\prime}$-DDD shows estrogenic activity and $p, p^{\prime}$-DDE shows antiandrogenic activity. ${ }^{37,38)}$ Further, methoxychlor is a proestrogen which requires demethylation by liver microsomal mixed function oxidase in animals prior to eliciting estrogenic activity. ${ }^{39,40)}$ Various pesticides might be converted to active estrogens by microsomal oxidase systems, though Sumida et al ${ }^{41)}$ showed that perimethorine was not metabolically activated. Some hydroxylated PCBs shows estrogenic activity. ${ }^{32,42,43)}$ Many polycyclic aromatic hydrocarbons present as environmental pollutants are negative in the estrogen screening test, but their hydroxylated metabolites may be estrogens, as in the case of benzo $[a]$ pyrene. ${ }^{44,45)}$ Elsby et al ${ }^{46,47)}$ predicted estrogenicity by means of a two-stage approach coupling human liver microsomes and a yeast estrogenicity assay. Methoxychlor, methoxybisphenol A and 3,17 $\beta$-bisdeoxyestradiol were positive. In addition to screening environmental contaminants for mutagenic and carcinogenic activities, it is also important to identify potentially hazardous proestrogens in our environment, taking account of the role of metabolic activities.

Acknowledgements This work was supported by a Grant-in-Aid for Scientific Research on a Priority Area (13027256) from the Japanese Ministry of Education, Science, Sports and Culture, and a Grantin-Aid for Scientific Research (C13672343) from the Japan Society for the Promotion of Science. 


\section{REFERENCES}

1) Colborn, T. (1995) Environmental estrogens: Health implications for humans and wildlife. Environ. Health Perspect., 103, 135-136.

2) Andersen, H. R., Andersson, A.-M., Arnold, S. F., Autrup, H., Barfoed, M., Beresford, N. A., Bjerregaard, P., Christiansen, L. B., Gissel, B. and Hummel, R., et al. (1999) Comparison of short-term estrogenicity test for identification of hormone-disrupting chemicals. Environ. Health Perspect., 107(suppl 1), 89-108.

3) Paris, F., Balaguer, P., Terouanne, B., Servant, N., Lacoste, C., Cravedi, J.-P., Nicolas, J.-C. and Sultan, C. (2002) Phenylphenols, biphenols, bisphenol-A and 4-tert-octylphenol exhibit $\alpha$ and $\beta$ estrogen activities and antiandrogen activity in reporter cell lines. Mol. Cell. Endocrinol., 193, 43-49.

4) Sugihara, K., Kitamura, S., Sanoh, S., Ohta, S., Fujimoto, N., Maruyama, S. and Ito, A. (2000) Metabolic activation of the proestrogens trans-stilbene and trans-stilbene oxide by rat liver microsomes. Toxicol. Appl. Pharmacol., 167, 46-54.

5) Sanoh, S., Kitamura, S., Sugihara, K. and Ohta, S. (2002) Cytochrome P450 1A1/2 mediated metabolism of trans-stilbene in rats and humans. Biol. Pharm. Bull., 25, 397-400.

6) Kitamura, S., Ohmegi, M., Sanoh, S., Sugihara, K., Yoshihara, S., Fujimoto, N. and Ohta, S. (2003) Estrogenic activity of styrene oligomers after metabolic activation by rat liver microsomes. Environ. Health Perspect., 111, 329-334.

7) Ambrose, A. M., Booth, A. N., DeEds, F. and Cox, A. J., Jr. (1960) A toxicological study of biphenyl, a citrus fungistat. Food Res., 25, 328-336.

8) Häkkinen, I., Hernberg, S., Karli, P. and Vikkula, E. (1973) Diphenyl poisoning in fruit paper production. Arch. Environ. Health, 26, 70-74.

9) Ohnishi, M., Yajima, H., Yamamoto, S., Matsushima, T. and Ishii, T. (2000) Sex dependence of the components and structure of urinary calculi induced by biphenyl administration in rats. Chem. Res. Toxicol., 13, 727-735.

10) West, H. D., Lawson, J. R., Miller, I. H. and Mathura, G. R. (1956) The fate of diphenyl in the rat. Arch. Biochem. Biophys., 60, 14-20.

11) Billings, R. E. and McMahon, R. E. (1978) Microsomal biphenyl hydroxylation: the formation of 3hydroxybiphenyl and biphenyl catechol. Mol. Pharmacol., 14, 145-154.

12) Haugen, D. A. (1981) Biphenyl metabolism by rat liver microsomes. Regioselective effects of inducers, inhibitors, and solvents. Drug Metab. Dispos., 9, 212-218.
13) Ahmed, S., James, K. and Owen, C. P. (2002) The design, synthesis, and biochemical evaluation of derivatives of biphenyl sulfamate-based compounds as novel inhibitors of estrone sulfatase. Biochem. Biophys. Res. Commun., 294, 180-183.

14) Ozawa, S., Ohta, K., Miyajima, A., Kurebayashi, H., Sunouchi, M., Shimizu, M., Murayama, N., Matsumoto, Y., Fukuoka, M. and Ohno, Y. (2000) Metabolic activation of $o$-phenylphenol to a major cytotoxic metabolite, phenylhydroquinone: role of human CYP1A2 and rat CYP2C11/CYP2E1. Xenobiotica, 30, 1005-1017.

15) Lowry, O. H., Rosebrough, N. J., Farr, A. L. and Randall, R. J. (1951) Protein measurement with the Folin phenol reagent. J. Biol. Chem., 193, 265-275.

16) Anstead, G. M., Carlson, K. E. and Katzenellenbogen, J. A. (1997) The estradiol pharmacophore: Ligand structure-estrogen receptor binding affinity relationships and a model for the receptor binding site. Steroids, 62, 268-303.

17) Fang, H., Tong, W., Perkins, R., Soto, A. M., Prechtl, N. V. and Sheehan, D. M. (2000) Quantitative comparisons of in vitro assay for estrogenic activities. Environ. Health Perspect., 108, 723-729.

18) Shi, L. M., Fang, H., Tong, W., Wu, J., Perkins, R., Blair, R. M., Branham, W. S., Dial, S. L., Moland, C. L. and Sheehan, D. M. (2001) QSAR models using a large diverse set of estrogens. J. Chem. Inf. Comput. Sci., 41, 186-195.

19) Hong, H., Tong, W., Fang, H., Shi, L., Xie, Q., Wu, J., Perkins, R., Walker, J. D., Branham, W. and Sheehan, D. M. (2002) Prediction of estrogen receptor binding for 58,000 chemicals using an integrated system of a tree-based model with structural alerts. Environ. Health Perspect., 110, 29-36.

20) Nishihara, T., Nishikawa, J., Kanayama, T., Dakeyama, F., Saito, K., Imagawa, M., Takatorim, S., Kitagawam, Y., Horim, S. and Utsumi, H. (2000) Estrogenic activities of 517 chemicals by yeast twohybrid assay. J. Health Sci., 46, 282-298.

21) Blair, R. M., Fang, H., Branham, W. S., Hass, B. S., Dial, S. L., Moland, C. L., Tong, W., Shi, L., Perkins, R. and Sheehan, D. M. (2000) The estrogen receptor relative binding affinities of 188 natural and xenochemicals: Structural diversity of ligands. Toxicol. Sci., 54, 138-153.

22) Branham, W. S., Dial, S. L., Moland, C. L., Bruce, L. M., Hass, B. S., Blair, R. M., Fang, H., Shi, L., Tong, W., Perkins, R. G. and Sheehan, D. M. (2002) Phytoestrogens and mycoestrogens bind to the rat uterine estrogen receptor. J. Nutr., 132, 658-664.

23) Meyer, T. and Scheline, R. R. (1976) The metabolism of biphenyl. II. Phenolic metabolites in the rat. Acta Pharmacol, Toxicol., 39, 419-432. 
24) Meyer, T., Aarbakke, J. and Scheline, R. R. (1976) The metabolism of biphenyl. I. Metabolic disposition of ${ }^{14} \mathrm{C}$-biphenyl in the rat. Acta Pharmacol. Toxicol., 39, 412-418.

25) Powis, G., Moore, D. J., Wilke, T. J. and Santone, K. S. (1987) A high-performance liquid chromatography assay for measuring integrated biphenyl metabolism by intact cells: Its use with rat liver and human liver and kidney. Anal. Biochem., 167, 191198.

26) Mole, M. L., Sanders, L. and Oglesby, L. A. (1988) High-performance liquid chromatography assay of biphenyl metabolism by hepatocytes cultured in an embryo/hepatocyte co-culture medium. Anal. Biochem., 175, 74-84.

27) Yamazoe, Y., Kamataki, T. and Kato, R. (1981) A sensitive method for determination of biphenyl hydroxylase activities using high-performance liquid chromatography. Anal. Biochem., 111, 126-130.

28) Weaver, D. E. and van Lier, R. B. L. (1986) Coupled $\beta$-cyclodextrin and reverse-phase high-performance liquid chromatography for assessing biphenyl hydroxylase activity in hepatic $9000 \mathrm{~g}$ supernatant. Anal. Biochem., 154, 590-595.

29) Soto, A. M., Fernandez, M. F., Luizzi, M. F., Karasko, A. S. O. and Sonnenschein, C. (1997) Developing a marker of exposure to xenoestrogen mixtures in human serum. Environ. Health Perspect., 105(suppl 3), 647-654.

30) Grossman, J. (1995) Dangers of household pesticides. Environ. Health Perspect., 103, 550-554.

31) Dodds, E. C. and Lawson, W. (1936) Synthetic estrogenic agents without the phenanthrene nucleus. Nature (London), 139, 996.

32) Garner, C. E., Jefferson, W. N., Burka, L. T., Matthews, H. B. and Newbold, R. R. (1999) In vitro estrogenicity of the catechol metabolites of selected polychlorinated biphenyls. Toxicol. Appl. Pharmacol., 154, 188-197.

33) Nakagawa, Y. and Tayama, K. (2001) Estrogenic potency of benzophenone and its metabolites in juvenile female rats. Arch. Toxicol., 75, 74-79.

34) Nakagawa, Y. and Suzuki, T. (2002) Metabolism of 2-hydroxy-4-methoxybenzophenon in isolated rat hepatocytes and xenoestrogenic effects of its metabolites on MCF-7 human breast cancer cells. Chem.-Biol. Interact., 139, 115-128.

35) Esaac, E. G. and Matsumura, F. (1980) Metabolism of insecticides by reductive systems. Pharmacol. Ther., 9, 1-26.

36) Kitamura, S., Shimizu, Y., Shiraga, Y., Yoshida, M., Sugihara, K. and Ohta, S. (2002) Reductive metabolism of p, $\mathrm{p}^{\prime}$-DDT and o, $\mathrm{p}^{\prime}$-DDT by rat liver cytochrome. Drug Metab. Dispos., 30, 113-118.
37) Kelce, W. R., Stone, C. R., Laws, S. C., Gray, L. E., Kemppainen, J. A. and Wilson, E. M. (1995) Persistent DDT metabolite $\mathrm{p}, \mathrm{p}^{\prime}$-DDE is a potent androgen receptor antagonist. Nature (London), 375, 581-585.

38) Chen, C. W., Hurd, C., Vorojeikina, D. P., Arnold, S. F. and Notides, A. C. (1997) Transcriptional activation of the human estrogen receptor by DDT isomers and metabolites in yeast and MCF-7 cells. Biochem. Pharmacol., 53, 1161-1172.

39) Kupfer, D. and Bulger, W. H. (1987) Metabolic activation of pesticides with proestrogenic activity. Fed. Proc., Fed. Am. Soc. Exp. Biol., 46, 1864-1869.

40) Stresser, D. M. and Kupfer, D. (1998) Human cytochrome P450-catalyzed conversion of the proestrogenic pesticide methoxychlor into an estrogen. Role of CYP2C19 and CYP1A2 in O-demethylation. Drug Metab. Dispos., 26, 868-874.

41) Sumida, K., Ooe, N., Nagahori, H., Saito, K., Isobe, N., Kaneko, H. and Nakatsuka, I. (2001) An in vitro reporter gene assay method incorporating metabolic activation with human and rat $\mathrm{S} 9$ of liver microsomes. Biochem. Biophys. Res. Commun., 280, 85-91.

42) Korach, K. S., Sarver, P., Chae, K., McLachlan, J. A. and McKinney, J. D. (1988) Estrogen receptorbinding activity of polychlorinated hydroxybiphenyls: conformationally restricted structural probes. Mol. Pharmacol., 33, 120-126.

43) Connor, K., Ramamoorthy, M., Moore, M., Mustain, M., Chen, I., Safe, S., Zacharewski, T., Gillesby, B., Joyeux, A. and Balague, P. (1997) Hydroxylated polychlorinated biphenyls (PCBs) as estrogens and antiestrogens: structure-activity relationships. Toxicol. Appl. Pharmacol., 145, 111-123.

44) Charles, G. D., Barteles, M., Zacharewski, T. R., Gollapudi, B. B., Freshour, N. L. and Carney, E. W. (2000) Activity of benzo[a]pyrene and its hydroxylated metabolites in an estrogen receptor- $\alpha$ reporter gene assay. Toxicol. Sci., 55, 320-326.

45) Fertuck, K. C., Matthews, J. B. and Zacharewski, T. R. (2001) Hydroxylated benzo[a]pyrene metabolites are responsible for in vitro estrogen receptor-mediated gene expression induced by benzo[a]pyrene, but do not elicit uterotrophic effects in vivo. Toxicol. Sci., 59, 231-240.

46) Elsby, R., Ashby, J., Sumpter, J. P., Brooks, N., Pennie, W. D., Maggs, J. L., Lefevre, P. A., Odum, J., Beresford, N., Paton, D. and Park, B. K. (2000) Obstacles to the prediction of estrogenicity from chemical structure: Assay-mediated metabolic transformation and the apparent promiscuous nature of the estrogen receptor. Biochem. Pharmacol., 60, 1519-1530.

47) Elsby, R., Maggs, J. L., Ashby, J., Paton, D., Sumpter, 
J. P. and Park, B. K. (2001) Assessment of the effects of metabolism on the estrogenic activity of xenoestrogens: A two-stage approach coupling hu- man liver microsomes and a yeast estrogenicity assay. J. Pharmacol. Exp. Ther., 296, 329-337. 